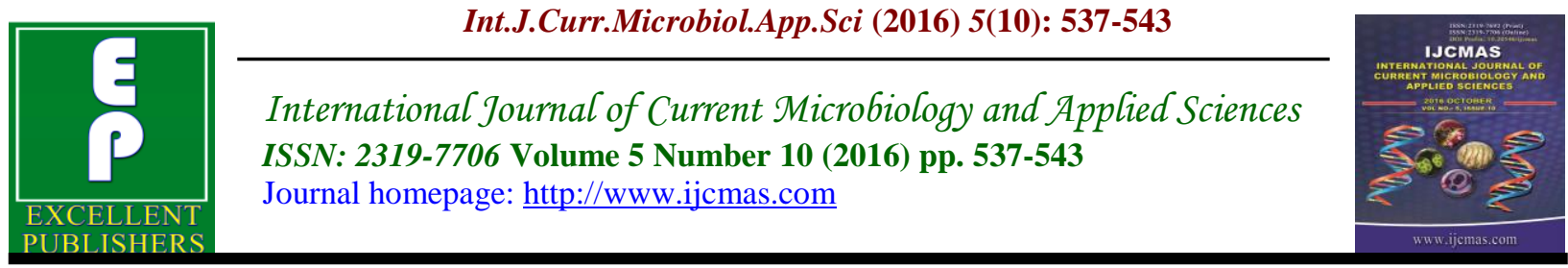

Original Research Article

http://dx.doi.org/10.20546/ijcmas.2016.510.060

\title{
In vitro, Alternative Methods to the Biological Control of the Aphids by Entomopathogenic Fungi Beauveria bassiana Isolates from Gaza Strip
}

\author{
Abboud El Kichaoui, Nedal Fayyad, Ameera El Hayek, Fareda Mosleh, Nadia Amara, \\ Wael Shehada, Emad Youssief and Mahmoud El Hindi*
}

\begin{abstract}
Biological Control Unit, Department of Biotechnology, Islamic University, Gaza, Palestine *Corresponding author
\end{abstract}

\section{A B S T R A C T}

Keywords

Aphids,

Entomopathogenic fungi, Beauvaria bassiana, biological control, Gaza Strip.

Article Info

Accepted:

20 September 2016 Available Online: 10 October 2016
Aphid's species is one of the most important insect pests which threaten most of crops in Gaza strip such as Mentha, Citrus, Rosa, Almond, Pomegranate, Fruits and most species of flowers. It has a rapid reproduction which cause a serious damage. Aphids' species are one of the main targets of Beauvaria bassiana which is used as safe prospects for the biological control of this pest. This study was carried out to find safer and environment solutions for pest's management by using entomopathogenic fungi (EPF) ( $B$. Bassiana). Spores of $B$. bassiana which is used as biological control agent in this study using Potato Dextrose Agar (PDA) media and liquid fermentation techniques. B. Bassiana fungus killed all adult aphids by $95 \%$ $97 \%$ compare to chemical treatment $50 \%$.

\section{Introduction}

Sustainable vegetable production it depends mainly on yield and quality, if not properly managed, pests and diseases can dramatically reduce crop yield, quality and subsequent returns. Plant diseases need to be controlled to maintain the quality and abundance of food, feed, and fiber produced by growers around the world (Pal and Gardener, 2006). Disease control is an essential component of crop management for increase yield potential. A low disease loss in your fields in the recent past does not ensure disease losses will remain low (Tobacco disease management (2015). Every year gardeners confront many insect pests feasting on fruits and vegetables (Jackman, 1998). Plants have many pests, such as aphids and mites. Aphids are important herbivores of both wild and cultivated plants that feed on the phloem of vascular plants (Züst and Agrawal, 2016). Most vegetables crops attached by this pest and also it can stunt and distort the growth of plants and cause wilting and bud drop, resulting in poor flowering and fruit set.

Synthetic pesticides have played a central role for control plant pathogen (Chandler et al., 2011; El-Wakeil, 2013). In the recent years, the negative effects on health and the environment as a result of the indiscriminate use of pesticides have led the EU to the prohibition of many synthetic pesticides (D'Addabbo et al., 2014). Consequently, 
some pest management researchers have focused their efforts on developing alternative methods to synthetic chemicals for controlling pest's plant pathogen (Pal et $a l ., 2006)$. A lot of studies encourage us to find solutions more realistic and safer to humans and environment-friendly for pest management. The development of resistance by many important insect pests led to increase chemical insecticides price used for pest control in addition the concern about the environment protection have encouraged studies to use of biological control (Laird et al., 1990; Slinninger et al., 2003; HaasCosta et al., 2011). Use of entomopathogenic fungi as biological control agents for insect species has increased the global attention during the last few decades (Latifian et al., 2014). B. bassiana is considered one of the most important entomopathogenic fungi that used as biocontrol agents. B. bassiana is used as an efficient bio-control agent for controlling several tea pests e.g. termites, thrips, whiteflies, aphids (Bani et al., 2014). The present study aims to use Entomopathogenic fungi $B$. bassiana that have wide host range against plant pathogens as fungal biopesticide on aphids.

\section{Materials and Methods}

\section{Chemicals and reagents}

Chemicals, cultures medium and reagents used in this study are shown in Table 1.

\section{Methodology}

\section{Isolation of fungi}

B. bassiana was isolated from dead of aphids found in the soil of one of the green house of infected citrus fields in Gaza strip. Soil sample was also collected from Gaza strip. The sample was placed into plastic bags and stored at $4-8{ }^{\circ} \mathrm{C}$ (NouriAiin et al., 2014).

\section{Culture of $B$. bassiana}

Selective medium and PDA Medium are generally required for isolation of $B$. bassiana from soil. DOC2 medium for $B$. bassiana, autoclaved and poured into Petri dishes (Shin et al., 2010). Soil sample (1g) from each isolate was suspended in sterile distilled water $(200 \mathrm{ml})$ containing Tween 80 as surfactant. Suspensions were applied on PDA and selection medium using streaking method. Plates were incubated at $25{ }^{\circ} \mathrm{C}$ in the total darkness.

Table.1 Chemicals and reagents used in this study

\begin{tabular}{|c|}
\hline Reagents \& Culture Media \\
\hline PDA Media \\
\hline PDB Media \\
\hline Chloramphenicol tablets \\
\hline Tween 20 \\
\hline Yeast Extract \\
\hline Peptone \\
\hline Crystal Violet \\
\hline Methylene Blue \\
\hline Agar \\
\hline
\end{tabular}

\section{Spore Suspension}

Potato Dextrose Broth (PDB) medium was prepared for the preparation of the spore suspension from fungi. PDB was autoclaved and inoculated with fungal spores propagated on PDA. Spores were harvested from 1 week old surface cultures by scraping and used to inoculate the liquid medium in flasks. The flasks were held on a shaker $(110 \mathrm{rpm})$ for 7 days at room 
temperature. The suspensions were stirred and filtered through a sterile Gauze to remove culture debris and mycelia. Spore concentration was adjusted using a haemocytometer and were calibrated to $2.5 \times 10^{7}$ spores $/ \mathrm{ml}$ for B. bassiana (Gindin et al., 2006; El kichaoui et al., 2016).

\section{Morphological Identification of Fungal Isolates}

Cultures were examined periodically and identified when they sporulated. The cultures were identified based on their morphological characteristics including growth pattern, colony texture, pigmentation, and growth rate of the colonies on PDA (Promputtha et al., 2005). When fungal colonies sporulated on PDA, small plaques from the edge and the center of each growing colony were transferred onto glass slides, and then were examined using a compound light microscope for characteristics of their vegetative and reproductive structures such as hyphal color and structures, shape and size of conidia and conidiophores (Yu, 2010).

\section{In vitro, Evaluation the influence of fungi against aphids}

\section{Divided the group}

Three groups of aphids were divided into (control, chemical and biological control $B$. bassiana). Each groups contain on 500 insect, air condition and nutrients at room temperature $25^{\circ} \mathrm{C}$ (Rashki \& shirvani, 2013).

The insects with the bio-insecticide $B$. bassiana at the concentrations of $2.5 \times 10^{7}$ spores $/ \mathrm{ml}$. Control samples were sprayed by water only, and chemical pesticides samples treated by Chlorofenapyr 240g/l and Thiocyclam hydrogen oxalate $50 \%$. The insects were examined every $24 \mathrm{hr}$, the percentage of infestation was calculated until the end of the experiment (Sabbour, 2014).

\section{Treatment in field}

We counted the aphids found in the plant areas for the three groups; we used the chemical pesticide on the second group for one time, and used our biological control agent $B$. bassiana of the third group for one time. Treatment of insects was done at the end of day before sunset.

\section{The counting}

We count the number of larvae's on the all tree in the three groups after $24 \mathrm{hr}, 48 \mathrm{hr}$ and $72 \mathrm{hr}$.

\section{Data Collection and Statistical analysis}

The effect of $B$. bassiana on aphids was tested using T-test. Statistical analyses were performed using the software SPSS Statistics 17.0 (SPSS Inc., 2009).

\section{Results and Discussion}

\section{Isolation of $B$.bassiana from the dead of Aphids}

B. bassiana was isolated from dead of aphids found in the soil, after removing the surface layer of soil and these samples shown in figure 1.

\section{Cultural Characteristics}

The cultural characteristics of $B$. bassiana isolates were examined. Generally, in culture, B. bassiana grows as a white mould. It produces many dry, powdery conidia in distinctive white spore balls. Each spore ball is composed of a cluster of conidiogenous cells shown in Figure $2 \& 3$. 


\section{Microscopic Examination}

Microscopic characters observation of $B$. bassiana was shape, size, color and thickness of hyphae, conidiophore, and conidium. Microscopic characters of $B$. bassiana was shown on figure 2 . Microscopic observation result show that hyphae size about 1-2 $\mu \mathrm{m}$ which grouped on conidiogene cells with 3-6 $\mu \mathrm{m}$ in size. Hyphae then branched and formed conidiogene cells with bottle like form, small neck, and branch long were up to more than $20 \mu \mathrm{m}$ and $1 \mu \mathrm{m}$ wide. Fertile hyphae was found on branch, circular and normally thicken or swollen. While mycelium which is hyphae aggregate of $B$. bassiana was white and insulated shown in Figure 4.

\section{Evaluation of influence of fungi against Aphids}

After adjustment of B. bassiana of concentration $2.5 \times 10^{7}$ spores $/ \mathrm{ml}$. Aphids on infected plants were treated by isolated fungi in vitro. Data in table 2 show the effect of bio-insecticide $B$. bassiana and chemical treatment against the Aphids for 3 days and based on collected data in table 2.the results were as follows:

The results in the current study reported that $B$. bassiana have exhibited satisfactory efficacy against Aphids compared to chemical treatment. This study recorded that; the entomopathogenic B. bassiana fungus could be caused larvae mortality up to $95-97 \%$, and the P-value as shown in table3.

Aphid has been a significant pest which threatens most of crops in Gaza strip such as Mentha, Citrus, Rosa and Ocimum basilicum. Despite advances in integrated pest management, and frequent use of insecticides, the industry is still plagued by the insect. There is a need to shift emphasis on biological control agents and softer chemicals (Ochieng \& Nderitu, 2011). Due to these problems, there was need to find alternative methods with different modes of action that would be effective, user and environment friendly.

Table.2 Shows the 3 groups of Aphids compare with the time of treatment.

\begin{tabular}{|c|c|c|c|c|}
\hline Treatment & Before Treatment & $\begin{array}{c}\text { After 24hr } \\
\text { Treatment }\end{array}$ & $\begin{array}{c}\text { After 48hr } \\
\text { Treatment }\end{array}$ & $\begin{array}{c}\text { After 72hr } \\
\text { Treatment }\end{array}$ \\
\hline Control & 500 & 530 & 543 & 800 \\
\hline chemical & 500 & 450 & 300 & 250 \\
\hline Fungus (B. bassiana $)$ & 500 & 350 & 150 & 25 \\
\hline
\end{tabular}

Table.3 Show the P-Value for all groups.

\begin{tabular}{|l|c|}
\hline \multicolumn{1}{|c|}{ Group } & P-value \\
\hline Control - Chemical & 0.045 \\
\hline Control - Fungus & 0.037 \\
\hline Fungus- Chemical & 0.016 \\
\hline
\end{tabular}


Fig.1 Soil samples that collected for B. bassiana isolation.

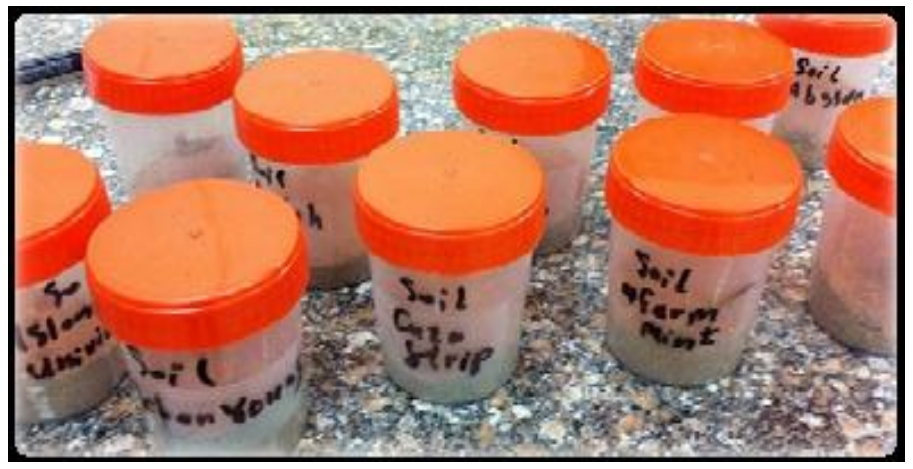

Fig.2\&3 Culture of B. bassiana on DOC2 Selective Medium and Culture of B. bassiana on PDA Medium
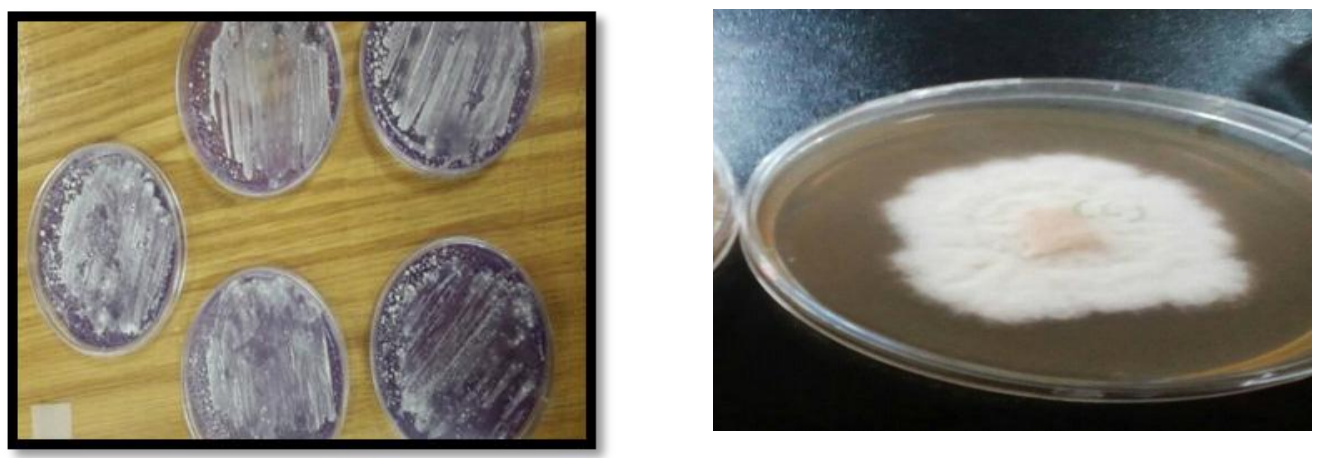

Fig.4 Microscopic examination for B. bassiana 1000X.

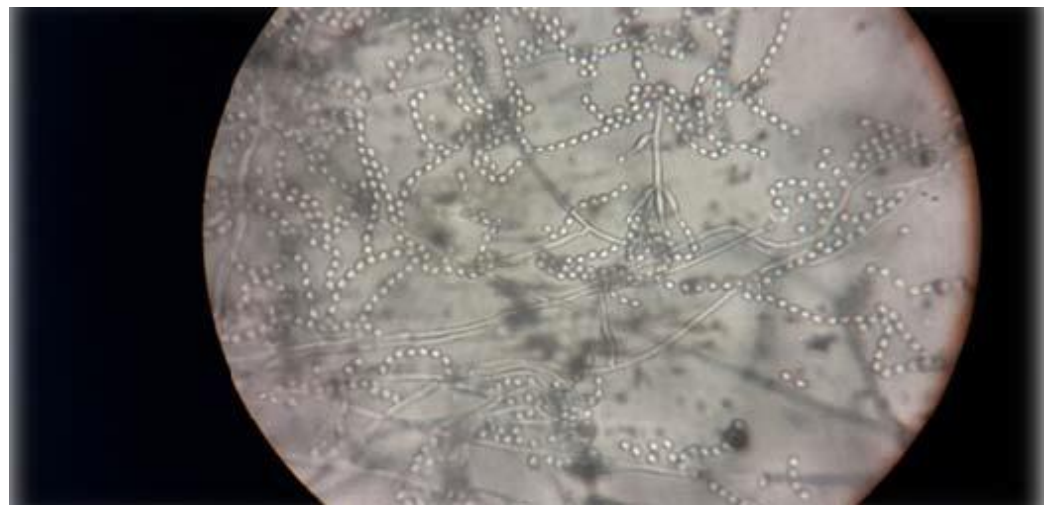

The effectiveness of entomopathogenic fungi $B$. bassiana as safe prospects for the biological control of aphid and the safe use of this fungus as a biological control where no negative effects on the surrounding environment and on the farmers and consumers health promote many studies to estimate the susceptibility of aphid to $B$. bassiana. The results indicate that the sample 1 \& 8 from $B$. bassiana isolates recorded the most effective isolates with aphid mortality up to $97 \%$. So the results in our study suggests that opportunities exist for revisiting aphid pest problems and the 
potential of $B$. bassiana as new tools to support a new biological control program targeting this insect.

In 2013, Rashki \& Shirvani Recent study has results which clarified the high significantly influenced of the Entomopathogenic fungi. B.bassiana strain DEBI008, to use integrated pest management (IPM) programs as an efficient biological control against the Aphid pest.

Based on recent study for using B.bassiana for controlling of Aphids and the maximum mortality observed by the highest concentration of $1 \times 10^{8}$ spores $/ \mathrm{ml}$ for $B$. bassiana and this insect pathogenic. Fungus can be used as potential biocontrol agent for the management of Aphids (Akmal et al., 2013).

In conclusion, the results from this study were encouraging to find new environmentally friendly product, the advantages of using of this product are to reduce the costs of pest control. Additionally it preserves human health and environment from pollution, which caused by chemical pesticides usage. Also it minimizes the formation of insecticides resistance in some pest.

\section{Acknowledgements}

The authors thank Department of biology and Biotechnology, Islamic University-Gaza for financial supporting and providing excellent research facilities.

\section{References}

Akmal, M., Freed, S., Malik, M.N., \& Gul, H.T. 2013. Efficacy of Beauveria bassiana (Deuteromycotina: Hypomycetes) against different aphid species under laboratory conditions. Pakistan J. Zool., 45(1): 7178.

Banik, A., Mukhopadhyay, S.K. 2014. A new report on rapid, cheap and easily extractable mass spore production of Beauveria bassiana using recyclable polyurethane foams as support medium. J. Microbiol. Biotechnol. Res.

Chandler, D., Bailey, A. S., Tatchell, G. M., Davidson, G., Greaves, J., \& Grant, W.P. 2011. The development, regulation and use of biopesticides for integrated pest management. Philosophical

Transactions of the Royal Society B: Biol. Sci., 366(1573): 1987-1998.

D'Addabbo, T., Laquale, S., Lovelli, S., Candido, V., \& Avato, P. 2014. Biocide plants as a sustainable tool for the control of pests and pathogens in vegetable cropping systems. Italian J. Agronomy, 9(4): 137-145.

Elkichaoi, A., Shafie, A., Muheisen, H., and Mosleh, F., El-Hindi, M., 2016. Safe approach to the Biological Control of the Tomato Leafminer Tuta absoluta by entomopathogenic fungi Beauveria bassiana isolates from Gaza Strip. Int. J. Appl. Res., 2(4): 351-355.

El-Wakeil, N.E. 2013. Botanical pesticides and their mode of action. Gesunde Pflanzen, 65(4): 125-149.

Gindin, G.L.E.V.S.K.I., Levski, S., Glazer, I., \& Soroker, V. 2006. Evaluation of the entomopathogenic fungiMetarhizium anisopliae and Beauveria bassiana against the red palm weevil Rhynchophorus ferrugineus. $\quad$ Phytoparasitica, 34(4): 370-379.

Jackman, John. 1998. Managing insect and mite pests in vegetable gardens. Texas AgriLife Extension Service Publication Number B-1300. Texas AgriLife Extension, Texas A\&M University System, College Station, TX. 55 pp. 
Laird, M., Lacey, L.A. and Davidson, E.W. 1990. Safety of microbial insecticides. Boca Raton, Florida, CRC Press, 259p.

Latifian, M., Rad, B., Amani, M., \& Rahkhodaei, E. 2013. Mass production of entomopathogenic fungi Beauveria bassiana Balsamo) by using agricultural products based on liquid-solid diphasic method for date palm pest control. Int. J. Agri. Crop Sci., 5(19): 2337.

NouriAiin, M., Askary, H., Imani, S., Zare, R. 2014. Isolation and characterization of entomopathogenic fungi from hibernating sites of Sunn Pest Eurygaster integriceps) on Ilam Mountains, Iran. Int. J. Curr. Microbiol. App. Sci., 3(12): 314-325.

NouriAiin, M., Askary, H., Imani, S., Zare, R. 2014. Isolation and characterization of entomopathogenic fungi from hibernating sites of Sunn Pest Eurygaster integriceps) on Ilam Mountains, Iran. Int. J. Curr. Microbiol. Appl. Sci., 3(12): 314-325.

Ochieng, S.O., Nderitu, P.W. 2011. Biocontrol approach to management of greenpeach aphid Myzus persicae in garden peas for a sustainable ecosystem. J. Horticulture and Forestry, 3(8): 231-237.

Pal, K.K., Gardener, B.M. 2006. Biological control of plant pathogens. The Plant Health Instructor, 2: 1117-1142.

Promputtha, I., Jeewon, R., Lumyong, S., McKenzie, E.H.C., \& Hyde, K.D. 2005. Ribosomal DNA fingerprinting in the identification of non sporulating endophytes from Magnolia liliifera
Magnoliaceae. Fungal Diversity.

Rashki, M., \& Shirvani, A. 2013. The effect of entomopathogenic fungus, Beauveria bassiana on life table parameters and behavioural response of Aphis gossypii. Bull. Insectol., 66(1): 85-91.

Rashki, M., \& Shirvani, A. 2013. The effect of entomopathogenic fungus, Beauveria bassiana on life table parameters and behavioural response of Aphis gossypii. Bull. Insectol., 66(1): 85-91.

Sabbour, M.M. 2014. Biocontrol of the Tomato Pinworm Tuta absoluta Meyrick) Lepidoptera: Gelechiidae) in Egypt. Middle East J. Agri. Res., 3(3): 499-503.

Shin, T.Y., Choi, J.B., Bae, S.M., Koo, H.N., Woo, S.D. 2010. Study on selective media for isolation of entomopathogenic fungi. Int. J. Industrial Entomol., 20(1): 7-12.

Slininger, P.J., Behle, R.W., Jackson, M.A., \& Schisler, D.A. 2003. Discovery and development of biological agents to control crop pests. Neotropical Entomol., 32(2): 183-195.

Tobacco disease management 2015. South Carolina Pest Management Handbook for Field Crops.

$\mathrm{Yu}$, J. 2010. Identification of fungi and bacteria associated with internally discolored horseradish roots Doctoral dissertation, University of Illinois at Urbana-Champaign.

Züst, T., Agrawal, A.A. 2016. Mechanisms and evolution of plant resistance to aphids. Nature plants, 2: 15206.

\section{How to cite this article:}

Abboud El Kichaoui, Nedal Fayyad, Ameera El Hayek, Fareda Mosleh, Nadia Amara, Wael Shehada, Emad Youssief and Mahmoud El Hindi. 2016. In vitro, Alternative Methods to the Biological Control of the Aphids by Entomopathogenic Fungi Beauveria bassiana Isolates from Gaza Strip. Int.J.Curr.Microbiol.App.Sci. 5(10): 537-543.

doi: http://dx.doi.org/10.20546/ijcmas.2016.510.060 